\title{
The STEM Interpreting Teaching Model for Undergraduate English Interpreting Majors
}

\author{
Wang Yunhua \\ Sias International College, Zhengzhou University, Xinzheng, China
}

Email address:

winheartwang@163.com

\section{To cite this article:}

Wang Yunhua. The STEM Interpreting Teaching Model for Undergraduate English Interpreting Majors. Science Journal of Education. Vol. 4, No. 2, 2016, pp. 46-52. doi: 10.11648/j.sjedu.20160402.15

Received: January 21, 2016; Accepted: March 29, 2016; Published: April 7, 2016

\begin{abstract}
The intensification of the world economic integration and the expansion of the domestic exchanges with foreign countries skyrocket the demand of interpreters in China, which is unlikely to be fully satisfied at present just because the training of interpreters is mainly included under the MTI programs. For this reason, it is of great significance to explore the feasibility of training interpreters at undergraduate level. Based on the review of the current domestic demands of interpreters in China, this paper sets out to introduce the "Stage-featured, Teacher and Expert-operated Multidimensional (STEM, for short) Interpreting Teaching Model" that was developed during the research and experiment in the undergraduate interpreting program in Sias International College, with the hope of providing experience for other similar study in this field.
\end{abstract}

Keywords: English, Interpreting Majors, Teaching Model

\section{Introduction}

With the intensification of the integration of the global economy, interpreting is now growing more and more important. Ever since 2000 when the Steering Committee of Foreign Language Majors Education at the Institutions of Higher Learning listed interpreting as a compulsory course, interpreting has been treated as part of the courses for English majors. In recent years, owing to the increasing demand for interpreters in the interpretation market, more and more importance is now being attached to the training of interpreters. By 2012, as many as 159 colleges and universities nationwide have begun to offer MTI programs [1] and 90 of them have started to offer interpretation courses at MTI level. A few strong colleges and universities have already started their endeavor to explore the feasibility in offering interpretation courses at undergraduate level. Mighty advances have been made in their efforts. Up till now, a compound framework of training interpreters at graduate and undergraduate levels has come into existence in China. Nevertheless, in terms of scale, the professional training of English interpreters in domestic colleges or universities is included chiefly in MTI programs with only a few attempts made at undergraduate level. As a result, it is hard to satisfy the increasing demand of interpreters in the interpretation market solely relying on the present training pattern. In accordance with the actual need of the interpretation market and on the basis of the advantage of higher internationalization of our college, we brought into operation the experiment in training undergraduate English interpreters in 2013, with the purpose of blazing a trail in English education and bringing up a new characteristic teaching model. After more than two years of hard work, a series of assignments such as the design of training program, the selection of candidates for interpreting major, the deployment of teachers, the provision of teaching equipment, etc., were completed in time. The interpreting major teaching shaped up nicely and the characteristic teaching model took shape ultimately.

From the angle of study or research in regard to interpretation, great advances have been made both in the western countries and in China. Focusing on five subjects of training, language, cognition, quality and profession in interpretation, the efforts of the past 50 years or so in the western countries gave rise to four study perspectives concerning the establishment of information processing paradigm, the advance of interpretive theory, the neurophysiological approach and Interdisciplinary empirical methods [2]. While in China, the study was conducted on both the theoretical and applied facets. The theoretical study 
touches upon the cognition, retention, mentality and behavior of the interpreter, the evaluation of interpretation quality as well as the interpreting profession while the applied study relates to interpreting teaching, interpreting major as well as interpreting experience and techniques [3]. Although plentiful research has been done into this domain with fruitful results, little experimental study is seen in general. In this connection, this paper, based on the experimental study that has been going on in the school of foreign languages of Sias International University, gives an account of the STEM model established in the experimental process by reviewing the actual demand of interpreters in China's interpretation market.

\section{The Actual Demand of Interpreters}

Professor Liu Heping described the actual need of domestic market for interpreters vividly with the sign of "pyramid"[4], which reflects three levels of demands that represent the needs of high-ranking interpreters, middle-ranking interpreters and low-ranking interpreters, as shown in Figure 1.

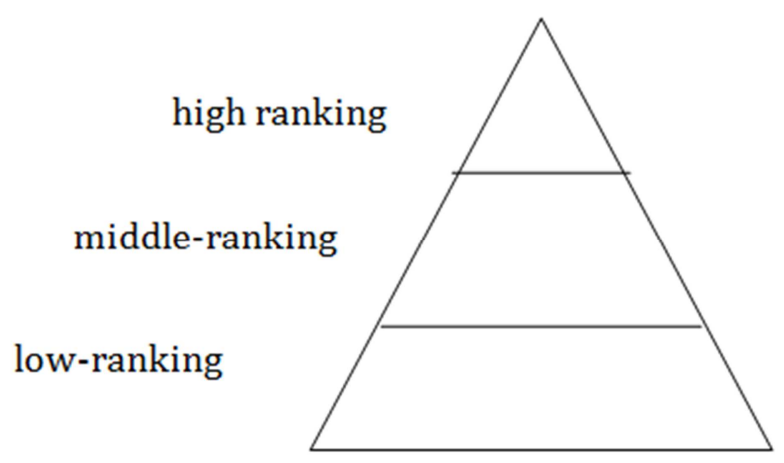

Figure 1. Three levels of demands.

The high-ranking interpreters refer to those who can offer consecutive interpretation or simultaneous interpretation service for the high level international conferences or events. They are positioned at the top of the pyramid but small in number. Since the international conferences or events are highly demanding, simultaneous interpretation is viewed as the high end of interpreting profession and consecutive interpreters are accordingly hailed as "golden-collars". Relevant data show that by 2012 there are totally more than 2,000 professional simultaneous interpreters all over the world and there are just less than 100 in China [5]. In recent years, with the increase of international litigation and arbitration affairs, the demand of court interpreters has soared up. Because of its special working environment and high requirement of legal knowledge, the court interpretation is also positioned at the top of interpreting profession. The middle-ranking interpreters mainly refer to the professional consecutive interpreters who can offer service in different fields. They are positioned in the middle of the pyramid but large in number. The low-ranking interpreters include those who can offer full-time or part-time service of liaison interpretation or consecutive interpretation in regard to the daily routines for the government agencies, enterprises and other organizations in China. This part is positioned at the bottom of the pyramid but the largest in number. According to the news released by the Web of Chinese Industry Research, currently there is a need for as many as one million interpreters and one thousand more high-ranking interpreters in China, and there is still not a single professional simultaneous interpreter now in the sectors of economy and trade, science and technology, politics and law, etc. [6].

As far as Henan is concerned, interpreters as well as translators, especially the high-ranking ones, are in increasing demand in the areas of administrative agencies, institutions and enterprises with the further opening of this province to the outside world and more frequent exchanges with foreign countries in respect of science, education, culture, health care, tourism and so on. At present, more than 4,000 non-professional interpreters are in service in the administrative agencies, institutions of higher learning, scientific research institutions, translation companies, enterprises and so on. As talents intensive organizations, the departments or offices of foreign affairs in this province now have just a total number of more than 150 non-professional interpreters, of whom only $20 \%$ are capable of offering quality service on formal occasions. At present, a rough estimate of more than 15,000 interpreters is needed in this province and the demand is going up year by year. On average as many as one hundred large-scale international conferences are held here in Henan each year. In peak seasons, interpreters are often in short supply and have to be hired form outside the province. The shortage of high-ranking interpreters has become a "bottleneck" [7] that hampers the further exchange of this province with foreign countries.

\section{The Novel STEM Teaching Model}

The huge demand for interpreters in China's interpretation market brings a golden opportunity for Sias International College to extend the channel for the cultivation of English majors. In accordance with the actual need in the interpretation market and on the basis of the advantage of this college in Sino-US cooperation in education, we set about exploring the feasibility of implementing the program of training English interpreting majors at undergraduate level. After more than two years' experiment, the characteristic training model was satisfactorily set up, which is defined as STEM interpreting teaching model and characterized as being stage-featured, teacher and expert-operated and multidimensional.

\subsection{Stage-Featured}

The four academic years of undergraduate college English teaching are divided into two stages by the Syllabus for English Major for Institutions of Higher Learning, which are the junior stage and the senior stage in detail. The former extends from the first academic year to the second year and aims at the impartment of English rudiments, the overall development and strict training of the students' basic skills, the cultivation of the students' abilities to use English language, 
good learning habits and correct learning methods, so as to lay a firm academic foundation for their progress in the following stage. The latter stretches from the third academic year to the fourth year and targets at the further development of the students' basic abilities, the acquisition of the knowhow related to English major, the expansion of knowledge scope, the elevation of the students' sensitivity to the intercultural differences and the improvement of the students' abilities to use English language in a comprehensive way [8]. Following the approach presented in the syllabus, we accordingly divided the four academic years into two stages: the stage of basic study and the stage of professional development. Different courses are preferred in either of the two stages. The first stage focuses on the students' acquisition of English rudiments and basic abilities, and the buildup of the students' practical use of English language as well as their basic skills of listening, speaking, reading and writing based on the fundamental courses such as comprehensive English, English listening, oral English, English reading and English writing, etc. The second stage concentrates on the cultivation of the students' acute cross-cultural awareness, the improvement of their interpreting skills, good professional quality and professional competence, on the basis of the major courses and by virtue of the initiation of basic theories, the improvement of skills and the organization of simulation practice.

In addition, as regards the students' choice of majors, we changed the traditional conventions and practice a little bit. Except for the existing three majors of business English, English translation and English education, the choice of English interpreting is only allowed to be made at the end of the stage of basic study rather than at the beginning of this stage. Putting in details, some of the students are shunted from the current three majors into a new area---- the major of interpreting. At the node of the two stages, precisely at the end of the second academic year, the candidates for the major of English interpreting are chosen based on the specific competitive tests. The tests are constituted of the preliminary selective test and the final selective test. The preliminary test is administered to single out 30 candidates who are proficient in both Chinese and English, good at spoken English, quick in thinking and response, and willing to take English interpreting as their major. Then they are organized to make up an experimental class that is managed on the basis of the principle of "temporary first and permanent last". In principle, the candidates are required to adhere to their original majors and study the subjects prescribed in the syllabuses of their majors in their original classrooms. While learning all the subjects required in the fourth semester, the candidates are gathered together on a temporary basis three times a week to study an extra subject----A Foundation Course of Interpreting. At the end of this semester, the final test is given to pick out 20 winners out of them as the permanent or regular members majoring in English interpreting. Form the fifth semester up, the 20 regular members are gathered to make up an independent class and study the subjects prescribed in the training program for the interpreting majors.

\subsection{Teacher and Expert-Operated}

"Teacher and expert-operated" refers to the cooperation between the teachers in the faculty team that is called team of double professionally titled teachers or DPT teachers. The term of "DPT teachers" was initially used to refer to the developmental objective of the teachers in the field of vocational education. As a striking attribute with regard to the construction of faulty team, it was advanced on the basis of the philosophy of vocational education that attaches paramount importance to the development of the learners' abilities. When it comes to the connotation, there still exists no agreed-upon definition currently just because people differ from one another greatly in understanding. Out of the existing views, four that were put forward by He Wenjin (2008), Tang Linwei, Zhou Mingxing (2005) and Zhu Xiaoping (2008), are thought to be representative and referential. The first one is "double certificates", which implies that these teachers are supposed to have two kinds of certificates each. One is a teachers' qualification certificate, the other is a technical certificate. The second is "double titles" that signifies that such a teacher has got a teachers' professional title and a non-teachers' professional title as well. The third is concerned with "source-relatedness" which indicates that the faulty team is made up of full-time professional teachers and part-time teachers who are technicians or experts invited from the enterprises or other fields. The fourth is "double qualifications", which denotes that such a teacher must be qualified in terms of the educational profession and a different profession exclusive of education [9] [10] [11]. Among the four views, the claim of "double qualifications" is generally preferred in higher education. It is universally acknowledged that this type of teacher is supposed to be qualified in two fields. In details, the teacher is supposed to be one who is a full-timer and has the intermediate technical title in education and in the meantime the teacher should also have at least two years of working experience in either primary industry or secondary industry or tertiary industry. In the area of professionalability-oriented education, a teacher with double professional titles is considered to be crucial to the development of the learner's future professional ability.

The ultimate goal of vocational education is to foster the learners' future professional abilities with the purpose of bringing up technical personnel to satisfy the actual needs of social and economic development. In the matter of technical personnel training, the DPT teachers play an irreplaceable role because they are in the position to integrate their professional knowhow and experience into their teaching work and apply themselves to the cultivation of technical personnel by upgrading the students' operational capabilities and innovative capacities. In a way, the interpretation instruction is also in duty bound to train the professional technical personnel in a special field and thus the DPT teachers play the same indispensable role in the training practice of professional interpreters. For this reason, the buildup of an excellent team of DPT teachers was put at the top of the agenda in our 
experimental program. With great effort, a team of DPT teachers with indigenous characteristics was finally built up and the STEM teaching model was successfully established along with it. Differently, the cooperation of the DPT teachers in this model is a compound concept that is similar to the third notion discussed above which alludes to two aspects of meanings: one is the cooperation of the Chinese teachers with the foreign teachers in basic courses; the other is the collaboration of the professional teachers with the professional experts in major courses. The concept is illustrated in the figure as following.

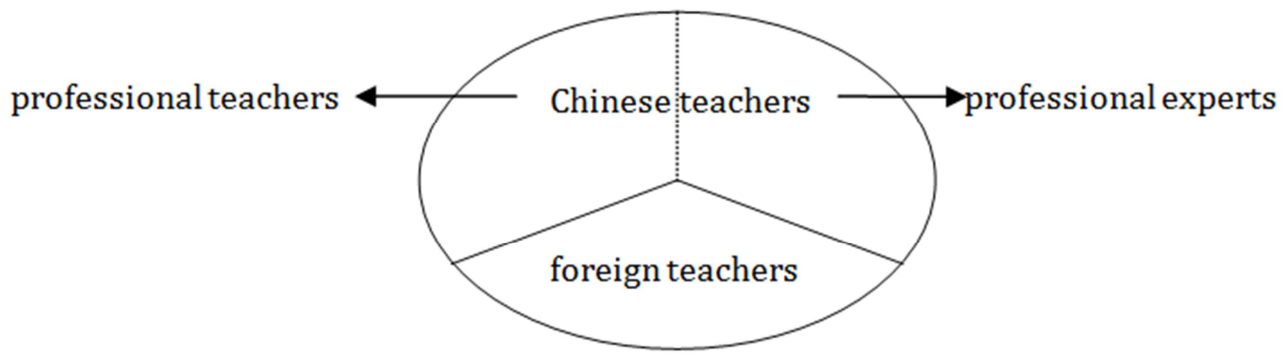

Figure 2. The cooperation of DPT teachers.

At present, as many as one third of the major courses are taught by foreign teachers and two third are taught by Chinese teachers. The former takes charge of the courses such as English conversation, English reading, English writing, a survey of Britain and the USA while the latter is in charge of the major courses like Chinese-English interpreting, English-Chinese interpreting, interpreting for foreign affairs, business interpreting, etc. The Chinese teachers are composed of professional teachers and professional experts from other professions. Right now in our faulty team, there is one full-time provincial-level senior translator, one full-time provincial-level associate senior translator and one part-time state-level senior translator. These three professors mainly teach practice-oriented major courses while the theory-based major courses and part of the skill-related courses are taught by the professional teachers.

The faulty team of DPT teachers with the characteristics of the cooperation of domestic teachers with foreign teachers and the collaboration of professional teachers with professional experts provides the students with an advantageous and distinctive learning environment that contributes to the steady improvement of the students' bilingualism, basic interpreting skills, application capabilities, professional competence as well as their professional attainments.

\subsection{Multidimensional}

The development of the learners' interpreting abilities is not only a process in which the learners receive and absorb the theories and knowledge, but also a process in which the learners practice, experience, introspect and improve themselves with regard to interpreting skills and professional attainments. In order to render the teaching and training more effective and productive, we stick to the principle of "combination of in-class and outside-class study, cooperation of intramural and extramural instructors, collaboration of domestic and foreign teachers, and integration of theory and practice" which is concluded as the multidimensional approach, as is shown in the following figure.

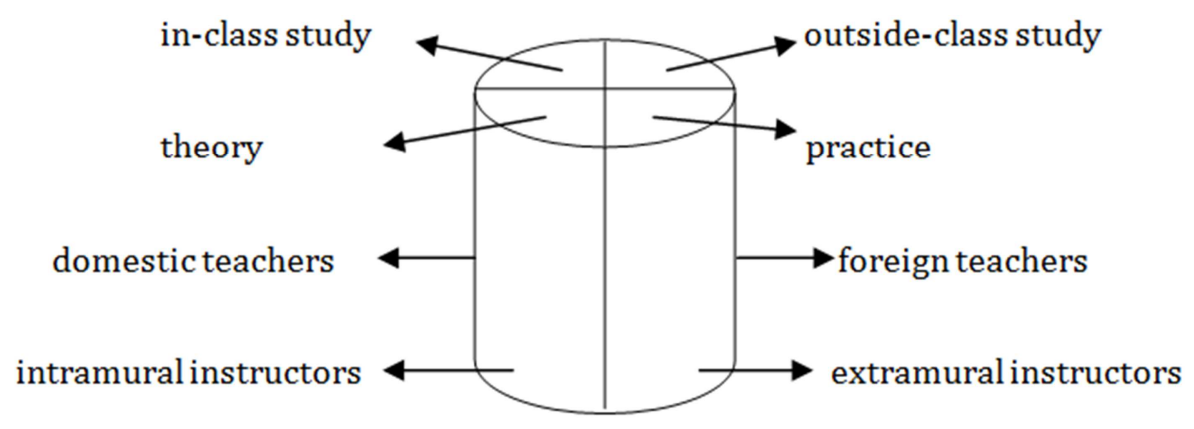

Figure 3. The multidimensional approach.

Interpreting is recognized to have such traits as immediacy and limitedness, stressing accuracy, smoothness and swiftness [12]. The interpreter is supposed to begin interpretation within three seconds after the speaker voice is over. In the whole process from the beginning to the end, he has no recourse to anybody or any dictionary. Therefore, to be accurate, smooth and swift, the trainee must be well versed with needful skills in addition to a good command of linguistic knowledge and extra-linguistic knowledge. However, as the acquisition of skills is dependent upon repeated practice and English interpreting is now being professionalized domestically in China, the interpreting instruction must be accordingly oriented towards the cultivation of professional interpreters with required professional abilities. To do so, it is in no case 
enough to rely merely on the limited hours in class after all. Instead the in-class learning must be integrated with the outside-class study and theory-based teaching must be combined with the practice-oriented instruction. For these reasons, we correspondingly introduced into our teaching practice during our experiment the following measures.

Firstly, as regards the teaching material, we made the best of internet and literature, and brought the updating and optimization to the teaching content on the basis of the course-books. In the meantime, we carefully chose different audio and video materials of different voices from different countries and regions, and used them to familiarize the students with different pronunciations and accents. In addition, we deliberately introduced the materials of different genres or types of literature, of proper difficulty and of good applicability into the classroom teaching, making sure that they cover various fields and focus on the students' future development. Furthermore, we drew a variety of activities into the teaching process to create as many opportunities as we could for the learners to experience the authentic scenes. For example, we added news reports and speech making, etc. to some of the major course lectures. In the classroom one student read the news and another student interpreted on site. All the others watched and took notes, and then made comments on what the interpreter had done. Such pair work was designed to start with Chinese-English interpretation followed by English-Chinese interpretation assignments and afterwards Chinese-English and English-Chinese interpretation activities went on alternatively. In this way, purposeful training activities were presented in a methodical and progressive way to boost the students' abilities to respond swiftly and to think critically, and help them to build up good psychological diathesis.

Secondly, specific learning tasks were assigned to the students to help them develop their self-taught habits based on the in-class instruction. Each semester we required each student to read 100 classic works or literary masterpieces or two classic novels and then wrote a book report. In addition, we required them to do practicing initiatively either in an individual manner or in a pair way. The per capita extra-curriculum practice was mandated to amount to 600 hours per year. For their convenience, we recommended to them three websites that include http://www.kouyi.org, http://cflc.xmu.edu.cn and http://www.tac-online.org.cn. On the one hand, they could refer to the websites for the audio and visual materials that they thought helpful to their practice and to the improvement of their skills and competence; on the other hand, they could observe the contestants' performance to discover their gaps to fill in. To make it a challenge, we specially demanded that each student attend one or two contests of either provincial level or state level and win at least one prize before graduation.

Thirdly, with reference to the integration of theory with practice, we abandoned the traditional didactic approach of lecturing and carried on the 3-Dimensional Principle that is characterized by the integration of theory with practice, the combination of rules with illustrations and cases, and the elaboration of methods with instances throughout the classroom teaching. In class, the elicitation and interaction methods were preferred to lead the students to discover, to think and to solve problems, with the boost of the learners' application capabilities and innovation capacities as the leading objective. Moreover, in the buildup of the students' intelligent structures that are suitable to their future careers, full play was allowed to the advantages of the professional experts who are more adept at bringing the connection of the knowhow acquisition with the professional experience and the experience with social production and social service. With regard to the combination of classroom instruction with extra-curriculum activities, we did what we could to make it possible for the students to get access to the extra-curriculum activities and provide them with useful advice and guidance in an effort to improve their abilities concerning swift response, mastery of message and skills of interpreting. Each semester the students were allowed to go out of the classroom and pitch in with the intramural and extramural events like international conferences, foreign exchanges, foreign tourism and so on, either as observers appreciating the interpreters' performance or as interpreters offering interpreting service. Putting themselves in the real interpreting settings, they experienced the real atmosphere, which is conducive to the growth of their psychological attainment and interpreting competence. For example, during our talk with the visiting professor from the Guam University, we deliberately had the students present at the meeting as interpreters interpreting for us both sides. What is more, we took initiative in establishing good relations with the extramural organizations and enterprises to afford the students more practice opportunities. In October, 2014, six students of the interpreting major were invited to do interpreting for SINO-MIE. They were highly acclaimed by the organizer and the customers for their quality interpreting service.

Apart from the extramural practice, we also managed to increase practice opportunities by offering the students four practical training hours each week. These practical classes were given by a Chinese teacher and a foreign teacher at the same time. They both prepared their lessons together on some specific topics before class and acted as the negotiators or conversationalists in class. The students acted as interpreters and took turns to do their jobs. Also, they were encouraged to bring recording devices and record or videotape their performances in class so that they could either appreciate and evaluate their own works or watch and learn from the others after class. The teachers would also give comments upon their works and give each of them advice on how to improve his product further.

As an effective supplement of classroom teaching, extracurricular activity and extramural practice function not only as a check-up and consolidation of what has been taught and learned in class, but also as a needful extension and sublimation of it. The cultivation of the learners' professional attainments and the improvement of their interpreting abilities are guaranteed via the integration of theory with practice and combination of intramural instruction with 
extramural practice.

Fourthly, in regard of the cultivation of bilingualism and the impartment of extra-linguistic knowledge, we insisted on the philosophy of Sino-foreign cooperative education in the total length of four academic years. In this connection, the domestic teachers and foreign teachers cooperated harmoniously in the teaching of major courses, which gave full play to the distinctive advantages of either side and brought with it a balanced development to the students' skills of listening, speaking, reading and writing. Moreover, in order to enlarge the learners' range of expertise in such areas as business, economy, laws and so on, we followed the principle of "two approaches employed side by side". The first approach was the intramural vertical collaboration that refers to the duly introduction and appropriate extension of the expertise by the professional teachers inside the school of foreign languages in the classes of major courses. The second was the extramural horizontal cooperation which refers to the students' acquisition of the expertise by attending the lectures given by the professional teachers in the other schools each semester. The introduction of vertical cooperation and horizontal collaboration not only made it possible to improve the students' professional abilities steadily on the basis of the advantages of the school of foreign languages and expand the students' range of expertise constantly by dint of the resources of the other schools, but also enabled the students to have easy access to the technical terms, basic knowhow, fundamental principles, operating procedures and business specifications in other fields, and laid a good foundation for their future careers as well.

Lastly, in matters of examination, we did not confine ourselves to the traditional ways like written test, on-site interpretation, recording, etc., but rather sought to get the evaluation mechanism diversified, contextualized and authenticated. For example, two or three students were arranged as a group to imitate a press conference, a meeting address or a business talk, etc., to exhibit genuinely who they were and what they had got. The evaluators rated their performance in accordance with relevant assessment rubrics or indicators, either scoring on site by observing or grading afterwards by referring to test-takers' recordings.

\section{Conclusion}

The changes in the demands of social and economic development for English talents not only pose a challenge for the undergraduate colleges and universities, but also provide an opportunity for the extension of their English majors. As a Sino-foreign cooperative, the relatively high degree of internationalization brought unique advantages to Sias International College. But at the same time, the homogeneity of traditional training model constituted a big challenge for this college as well with regard to the wound-be learners and the employment prospects of the graduates. In accordance with the real demands of the interpretation market and on the basis of the advantages of this college, we made a bold attempt and salutary exploration in the development of undergraduate
English major, ultimately opening up a new way to foster English interpreting majors and forming the characteristic STEM teaching model for interpreting majors.

During our research and experiment of more than two years, the model aimed at the formation of the students' intelligent structure and professional abilities suitable to their future careers by means of developing the students' bilingualism, widening the students' range of knowhow, enriching the students' extra-linguistic knowledge, consolidating the students' interpreting skills and enhancing the students' professional attainments. With this characteristic model we succeeded in extending the English major into a new field, perfecting the training mechanism of English personnel and finding a new way of facilitating the sustainable development of the college, in addition to the cultivation of interpreters demanded by the society. Herein the present author would like to avail himself of the limited space of the pages to express the sincere hope that the STEM teaching mode introduced above be referential to the readers in the similar field of research.

\section{Acknowledgement}

This paper is sponsored by (1) "The Program of the 8th Key Subjects of Henan Province"; and (2) "The Program of Brand Disciplines for Henan Private Institutions of Higher Education".

\section{References}

[1] Ran Yonghong. The Undergraduate Interpreting Teaching in the New Situation [J]. Chinese Translators, 2013, 34 (5): 45-48.

[2] Jiang Fengxiao, Wu Zhan. Interdisciplinary construction: Overview on interpreting study abroad [J]. China Adult Education, 2011, (3): 148-149.

[3] Liu Xiaoqing. Overview on China's interpretation study from 2000 to 2012[J]. Languages Journal, 2013, (7): 61-64.

[4] Liu Heping. On the principles and methods in undergraduate interpreting teaching [J]. Chinese Translators, 2009, (6): 34-41.

[5] Hebei Foreign Studies University News. Occupation prospects: domestic shortage of simultaneous interpreters [EB/OL]. http://www.hbwy.com.cn/1010new/onews.asp?id=2288, 2012-07-09/2015-111-18.

[6] Industry Study. An analysis of the prospects of simultaneous interpretation and investment risk forecast in 2010-2015 [EB/OL].

http://www.chyxx.com/research/201009/664128X6WO.html. 2010-09-07/2015-11-18.

[7] Wangdan, Liu Yining. The shortage of interpreters constitutes the bottleneck for the foreign exchange in our province $[\mathrm{N}]$. Henan Daily, $5^{\text {th }}$ edition, Wednesday, July 4, 2012.

[8] The English Team of the Steering Committee of Foreign Language Majors Teaching at Institutions of Higher Learning. English Syllabus for College and University English Majors [M]. Beijing: Foreign Language Teaching and Research Press, 2000 . 
[9] He Wenjin. The concept of the DPT teachers [J]. Vocational Education Communication: Journal of Jiangsu Teachers' College of Technology, 2008, 23(8): 49-51.

[10] Tang Linwei, Zhou Mingxing. Review of the DPT teachers at vocational colleges [J]. Journal of Henan Vocational Technical Teachers' College (Vocational Education Edition), 2005, (4): 30-33.
[11] Zhu Xiaoping. The Concept of the DPT teachers: the past, present and future [J]. Vocational Education Forum, 2008, (7): 26-28.

[12] Lei Tianfang, Chen Qing. A Course for Interpreting [M]. Shanghai: Shanghai Foreign Language Education Press, 2006. 